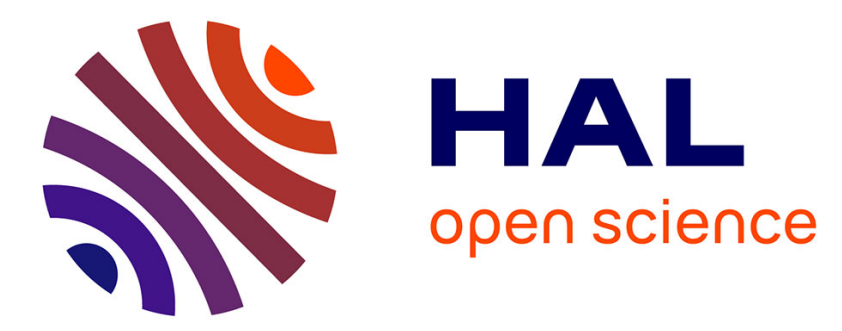

\title{
Correlation of crystal defects and bipolar device behaviour
}

D. Kranzer, R. Lemme, B.O. Kolbesen, K.R. Mayer, H. Strunk

\section{To cite this version:}

D. Kranzer, R. Lemme, B.O. Kolbesen, K.R. Mayer, H. Strunk. Correlation of crystal defects and bipolar device behaviour. Revue de Physique Appliquée, 1978, 13 (12), pp.803-807. 10.1051/rphysap:019780013012080300 . jpa-00244550

\section{HAL Id: jpa-00244550 https://hal.science/jpa-00244550}

Submitted on 1 Jan 1978

HAL is a multi-disciplinary open access archive for the deposit and dissemination of scientific research documents, whether they are published or not. The documents may come from teaching and research institutions in France or abroad, or from public or private research centers.
L'archive ouverte pluridisciplinaire HAL, est destinée au dépôt et à la diffusion de documents scientifiques de niveau recherche, publiés ou non, émanant des établissements d'enseignement et de recherche français ou étrangers, des laboratoires publics ou privés. 


\title{
CORRELATION OF CRYSTAL DEFECTS AND BIPOLAR DEVICE BEHAVIOUR (*)
}

\author{
D. KRANZER, R. LEMME, B. O. KOLBESEN, K. R. MAYER
}

Siemens AG, 8 München 80, Balanstr. 73

and

\section{H. STRUNK}

Max-Planck-Institut für Metallforschung, Stuttgart, Germany

\begin{abstract}
Résumé. - L'analyse des transistors bipolaires indique, qu'il est possible d'établir une corrélation entre les caractères des transistors et certains défauts cristallographiques. Pour cela on examine multiémetteur et unique-émetteur transistor en technologie 3D, à l'aide de décoration anodique, de topographie aux rayons $\mathrm{X}$ et de microscopie électronique à très haute tension. Comme les micro-fissures ou/et les dislocations sont la cause pour les courants de fuite $I_{\text {CEO }}>10^{-4}$ A zéro ou quelques dislocations dans les émetteurs avec $I_{\text {CEO }}<10^{-7}$ A pouvaient être démontrées.
\end{abstract}

\begin{abstract}
A correlation of crystal defects and the electrical characteristics of multi- and single emitter devices, fabricated with a triple diffusion process, is presented. Anodic decoration, etching techniques, X-ray topography and high voltage transmission electron microscopy is utilized to locate and analyse the crystal defects. A histogram of the leakage current $I_{\text {CEO}}$, of the multi-emitter devices shows two peaks at low $\left(I_{\text {CEO }}<10^{-7} \mathrm{~A}\right)$ and high $\left(I_{\text {CEO }}>10^{-4} \mathrm{~A}\right)$ values of $I_{\text {CEO }}$, respectively. The comparatively small peak at the high $I_{\text {CEO }}$ level is caused by microcracks and/or dislocations of high density $\left(10^{8} \mathrm{~cm}^{-2}\right)$. No or a few dislocations have been found for devices pertaining to the group of $I_{\text {CEO }}<10^{-7} \mathrm{~A}$.
\end{abstract}

1. Introduction. - The yield of bipolar integrated circuits is limited by photolithography, metallization and native and process induced crystal defects. The effect of the latter on yield is enhanced in modern bipolar technology because of the higher complexity (larger emitter area), the higher speed (shallow diffusions, oxide isolation [1]) and the low power dissipation requirements.

In this paper we discuss the correlation of crystal defects and electrical characteristics of bipolar devices such as multi-emitter structures (power devices), single emitter transistors and diodes. These devices have been fabricated using a triple diffusion (3D [2]) technology.

As compared with devices produced on epitaxial layers [1] fewer crystal defects are observed. Especially, high density dislocation networks do not show up in devices fabricated by the 3D-process. In section 2 the fabrication of the devices and the experimental methods to analyse them are briefly discussed. The experimental results are presented in section 3 .

2. Experimental. - The fabrication of the device proceeds as follows : CZ-silicon is used as starting material. Oxide isolation, phosphorus ion implan-

(*) This work was partly supported by the Federal Department of Research and Technology of the FRG. The authors alone are responsible for the content.

tation, collector well drive in at $1220^{\circ} \mathrm{C}$ for $140 \mathrm{~min}$. collector contact diffusion at $1020^{\circ} \mathrm{C}$, base implantation, base contact diffusion and emitter diffusion. Silicon nitride is used for passivation. In all process steps except in the case of the collector well and the collector contact diffusion a temperature below $1000^{\circ} \mathrm{C}$ has been used (Fig. 1).

Triple diffusion ( $3 D$ ) process

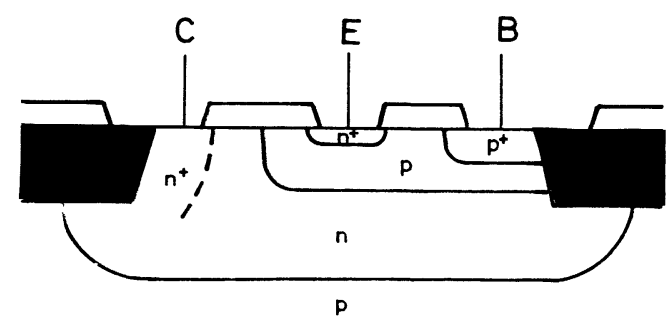

Epitaxial layer process

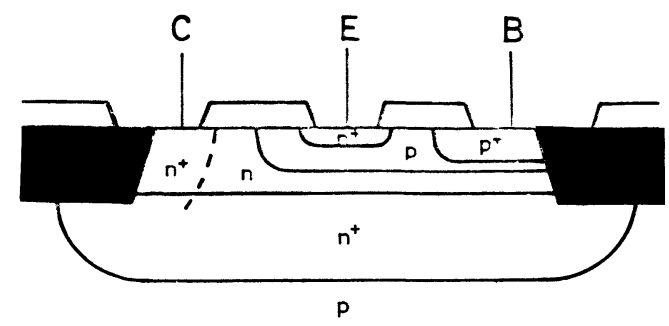

FIG. 1. - Cross-sections of 3D- and epilayer transistor. 
Table I shows the experimental techniques applied for monitoring and analysing crystal defects and the electrical device characteristics being correlated with crystal defects.

\section{TABLE I}

\section{Detection techniques and device characteristics}

\section{Detection techniques}

Electrical device measurements

Anodic decoration

$\mathrm{X}$-ray topography

Etching techniques

High voltage transmission electron microscopy

\section{Device characteristics}

Diode characteristic : Forward/reverse

Emitter-collector characteristic : Leakage current

The anodic decoration method [3] is very handy to make leaky emitter-collector complexes visible. With respect to the leakage current a threshild exists below which hardly any information can be utilized. X-ray topography [4] was applied for the purpose to obtain an overall view of the wafer and to locate regions where crystal defects are most likely to exist. By this method one is enabled to distinguish roughly between a good and a bad wafer with respect to crystal imperfections. X-ray topography is also used to study the change of crystal imperfections due to a specific process step. Higher resolution is obtained by preferential etching [4] and particularly by high voltage transmission electron microscopy (HV-TEM) $[5,6]$. By HV-TEM at $650 \mathrm{keV}$ samples up to $4 \mu \mathrm{m}$ thick can be investigated permitting the study of the emitter base collector complex simultaneously [5, 6]. Utilizing the stereo technique the location and extension with respect to the pn-junction and the device geometry can be determined (uncertainty $\pm 0.1 \mu \mathrm{m}$ ). For the purpose of the electrical characterization a measurement set up was available to measure the leakage current on single emitter devices $\left(3 \times 8 \mu \mathrm{m}^{2}\right)$.

A map of the leakage current of single and multiemitter devices was first made in order to select the devices for further investigations. The reverse current voltage characteristic of the emitter-base and basecollector diode and the emitter collector leakage current was measured. Anodic decoration and preferential etching was mainly applied to confirm the results obtained by the electrical measurements. Finally, about 20 single emitter devices have been investigated by TEM.

3. Results and discussion. - A drastic change of the emitter window color appears after anodic decoration (voltage $25 \mathrm{~V}$, for $10 \mathrm{~min}$.) if the leakage current $I_{\mathrm{CEO}}$ at $2 \mathrm{~V}$ exceeds approximately $10^{-5} \mathrm{~A}$ $\left(40 \mathrm{~A} / \mathrm{cm}^{2}\right)$. With $I_{\text {CEO }}$ below $10^{-5}$ A occasionally the emitter window is lightly colored but it is hardly possible to identify the color. The threshold value changes if the condition of the decoration is changed. On wafers with a power device yield exceeding approximately $70 \%$ (a device is considered to be good if $I_{\text {CEO }}<10^{-5} \mathrm{~A}$ at $2.5 \mathrm{~V}$ ) usually one emitter out of 400 is decorated for a 400 emitter device. The measurement of $I_{\mathrm{CEO}}$ is therefore a suitable procedure to determine and monitor the crystal defect density for the purpose of yield analysis.

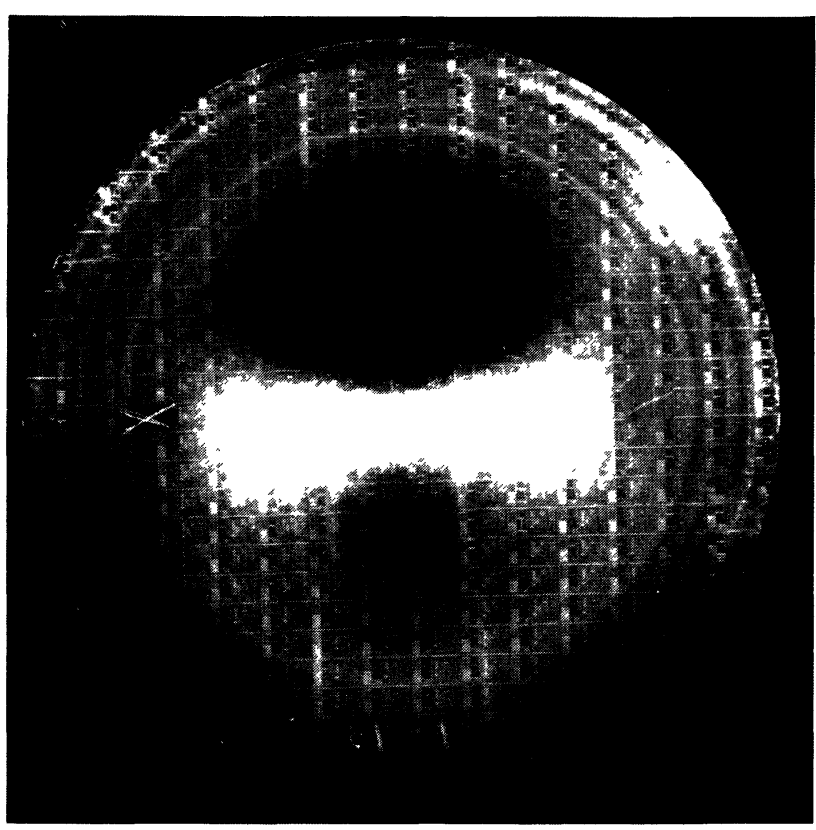

a)

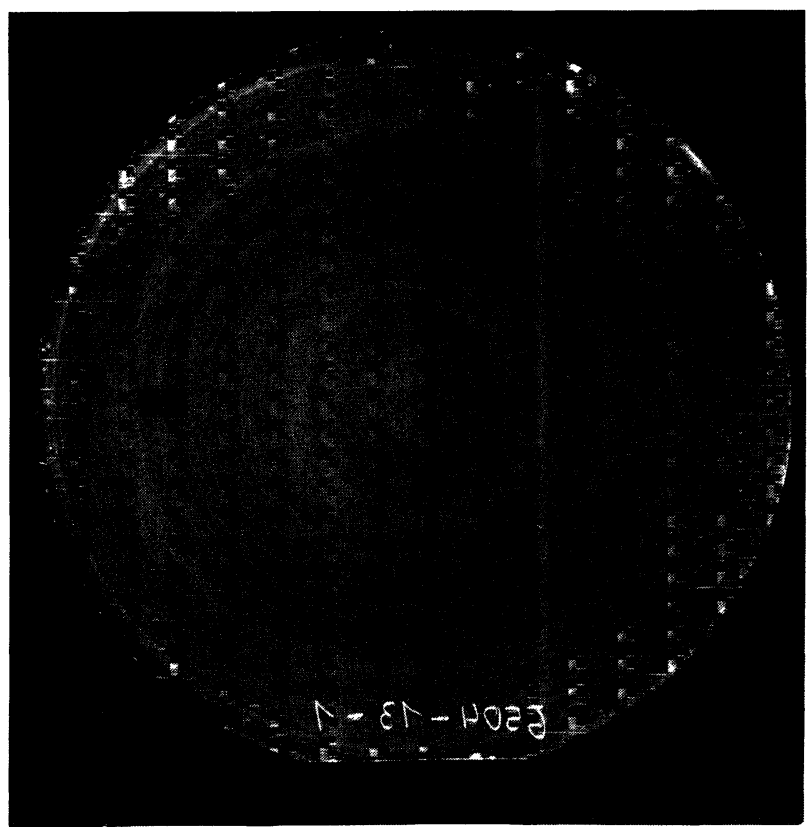

b)

FIG. 2. - Transmission-X-ray topographs of $3^{\prime \prime}$ wafers after device processing. a) Low device yield due to high dislocation density $\left(10^{7} \mathrm{~cm}^{-2}\right)$ in the center of the wafer. $\left.b\right)$ High device yield due to low density of crystal defects. The ring-like pattern in $a$ ) and $b$ ) is caused by oxygen precipitates in the bulk of the wafers. 
The X-ray topographs in figure 2 represent a typical example of a good (Fig. $2 b$ ) and a bad (Fig. $2 a$ ) wafer. The regions of intense contrast correspond to regions of a high density of crystal imperfections [4].

In figure $3 a$ a histogram of $I_{\text {CEO }}$ of the power device as measured by an automatic testing set up is shown. Figure $3 a$ depicts the case of a lot with an average power device yield of $75 \%$ while in figure $3 b$ an average yield of $92 \%$ is shown. Two peaks are easily observed : at $I_{\text {CEO }}<10^{-7} \mathrm{~A}\left(10^{-7} \mathrm{~A}\right.$ is the lower limit of the measurement set up) and at $I_{\text {CEO }}>10^{-4} \mathrm{~A}$. It will be shown below that different types and/or different densities of crystal defects exist for devices pertaining to the group of low and high values of $I_{\mathrm{CEO}}$, respectively.
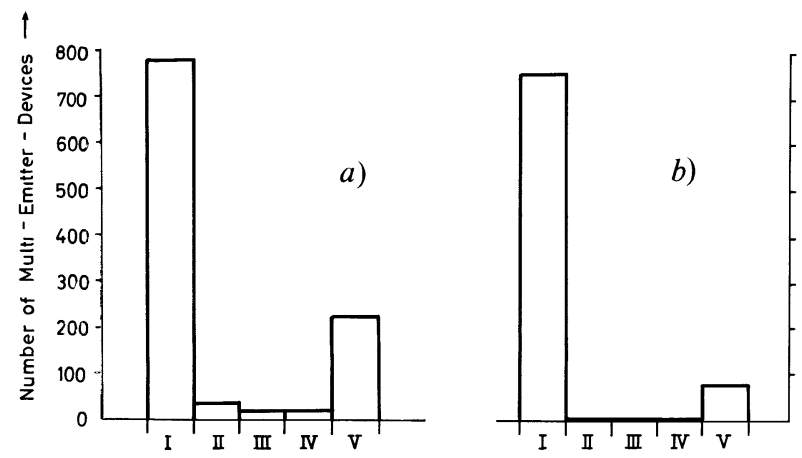

Fig. 3. - Histogram of $I_{\text {CEO }}$ of multi-emitter devices for a lot with an average yield of $75 \%(a)$ and $92 \%(b)$, respectively. The groups I to $\mathrm{V}$ denote the following $I_{\text {CEO }}$ values : I $: I_{\text {CEO }}<10^{-7} \mathrm{~A}$; II $: 10^{-7} \mathrm{~A}<I_{\text {CEO }}<10^{-6} \mathrm{~A}$; III $: 10^{-6} \mathrm{~A}<I_{\text {CEO }}<10^{-5} \mathrm{~A}$; IV : $10^{-5} \mathrm{~A}<I_{\text {CEO }}<10^{-4} \mathrm{~A} ; \mathrm{V}: 10^{-4} \mathrm{~A}<I_{\text {CEO }}$.

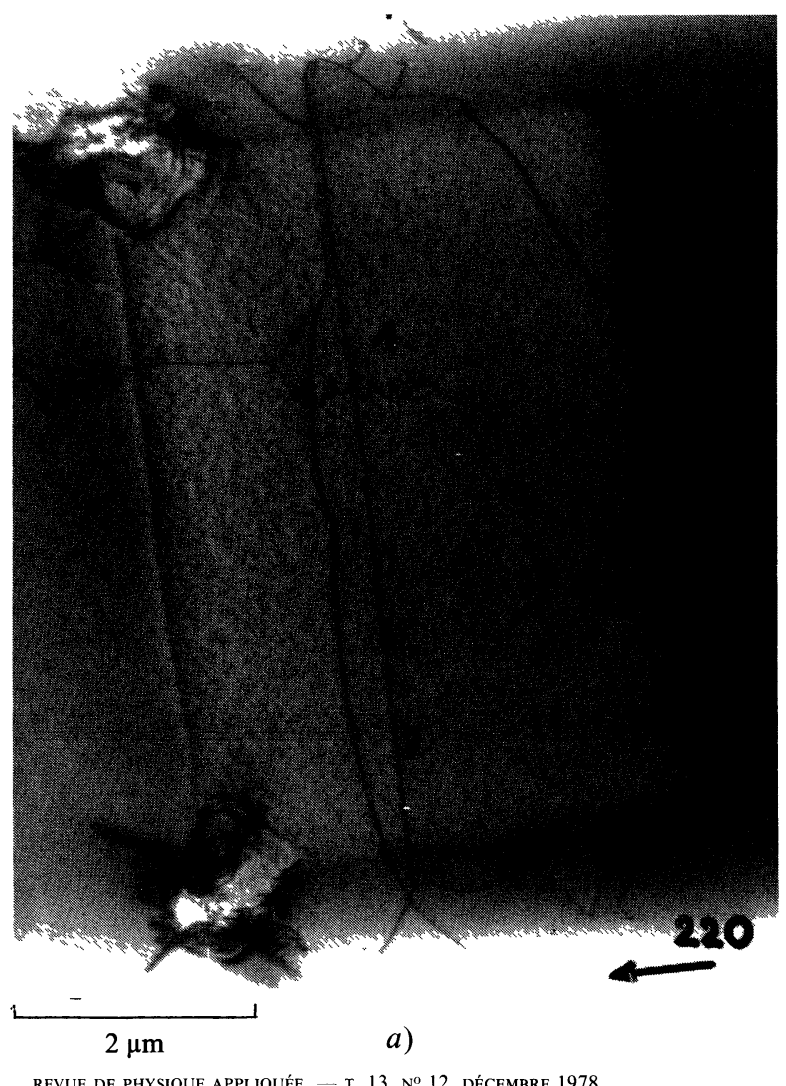

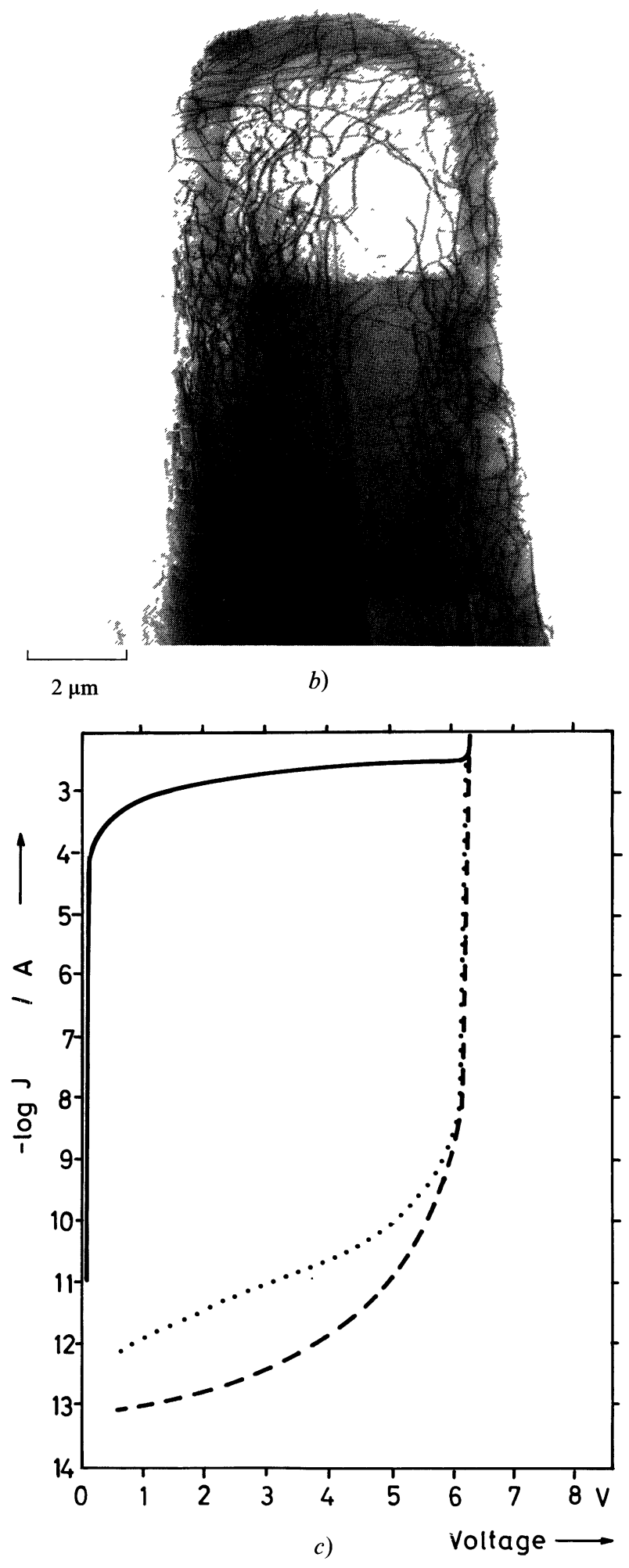

FIG. 4. - Transmission electron micrographs $(650 \mathrm{kV})$ and electrical characteristics of transistors with high leakage currents $\left(10^{-4} \mathrm{~A}\right)$. a) Microcracks at two corners of the emitter and a helical dislocation (1) are penetrating both pn-junctions of a defective 3D-transistor. The high $I_{\text {CEO }}$ value is mainly caused by the microcracks. $b$ ) Oxide-edge dislocations in high density $\left(10^{8} \mathrm{~cm}^{-2}\right)$ running through the pn-junctions of a defective transistor in epitaxytechnology. c) Electrical characteristic : $I_{\mathrm{CEO}} / U_{\mathrm{CE}}(-), I_{\mathrm{CB}} / U_{\mathrm{CB}}$ $(-\cdots), I_{\mathrm{EB}} / U_{\mathrm{EB}}(\cdots)$. 
The transmission electron micrograph of figure $4 a$ shows a typical example of crystal defects found in a defective 3D-transistor of the $I_{\mathrm{CEO}}$-group $>10^{-4} \mathrm{~A}$ (Fig. 4c). By stereo microscopy it could be established that the microcracks and the helical dislocation 1 are penetrating both pn-junctions whereas all other dislocations are running below the base region. The main contribution to the high $I_{\text {CEO }}$ value results from the microcracks located at two of the corners of the emitter area. Similar high $I_{\text {CEO }}$ values have been observed for defective single transistors produced on epitaxial layers [1]. Those transistors contain a dense array of oxide-edge dislocations of which a large number is crossing both pn-junctions simultaneously (Fig. 4b). Transistors of medium leakage current levels $\left(I_{\mathrm{CEO}}=10^{-7}-10^{-5} \mathrm{~A}\right)$ generally exhibit a small number of dislocations which are penetrating both pn-junctions (Fig. 5a, $b$ ).

In good transistors no crystal defects or a few dislocations were found (Fig. 6a). As ascertained by stereo microscopy the dislocations in figure 6 did not cross the emitter-base and base-collector pn-junctions simultaneously. In the devices studied dislocations

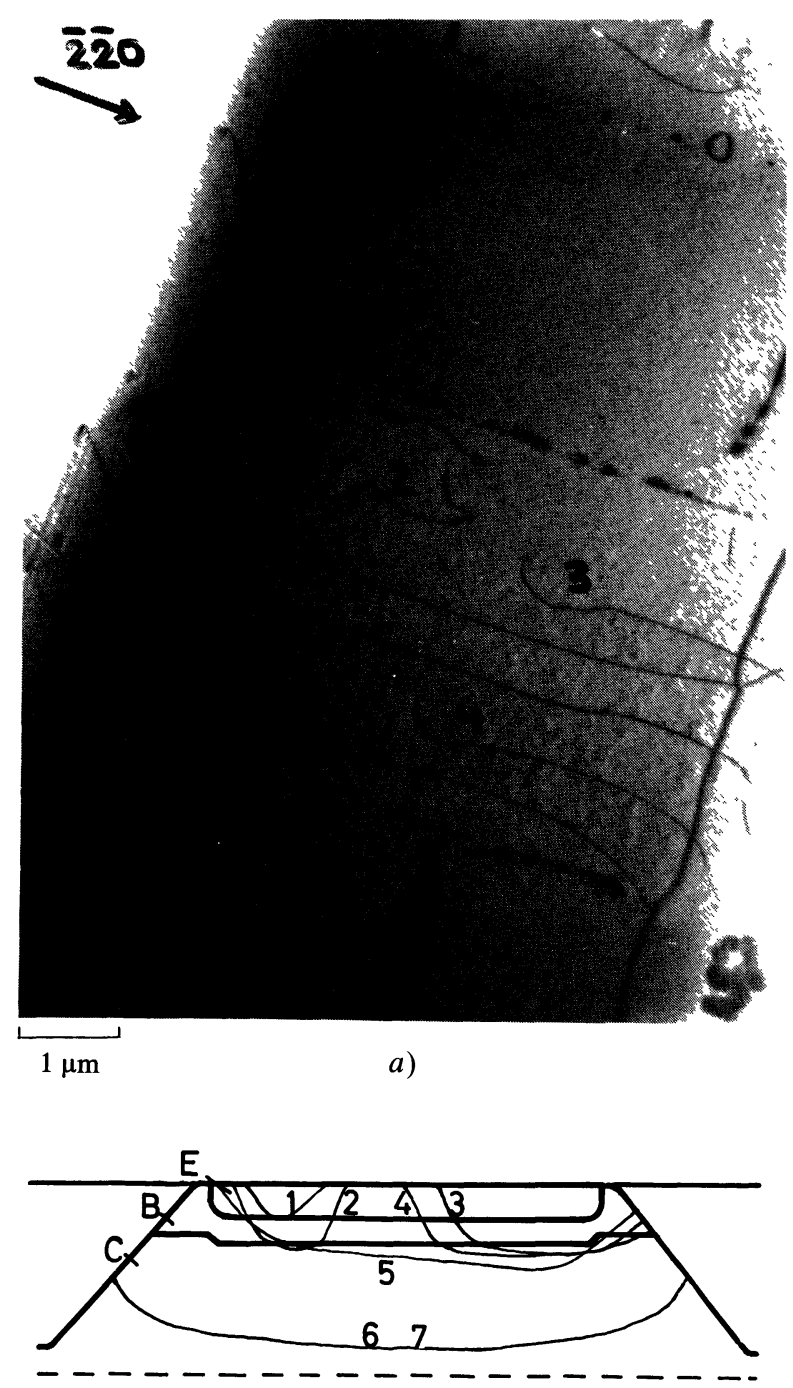

b)

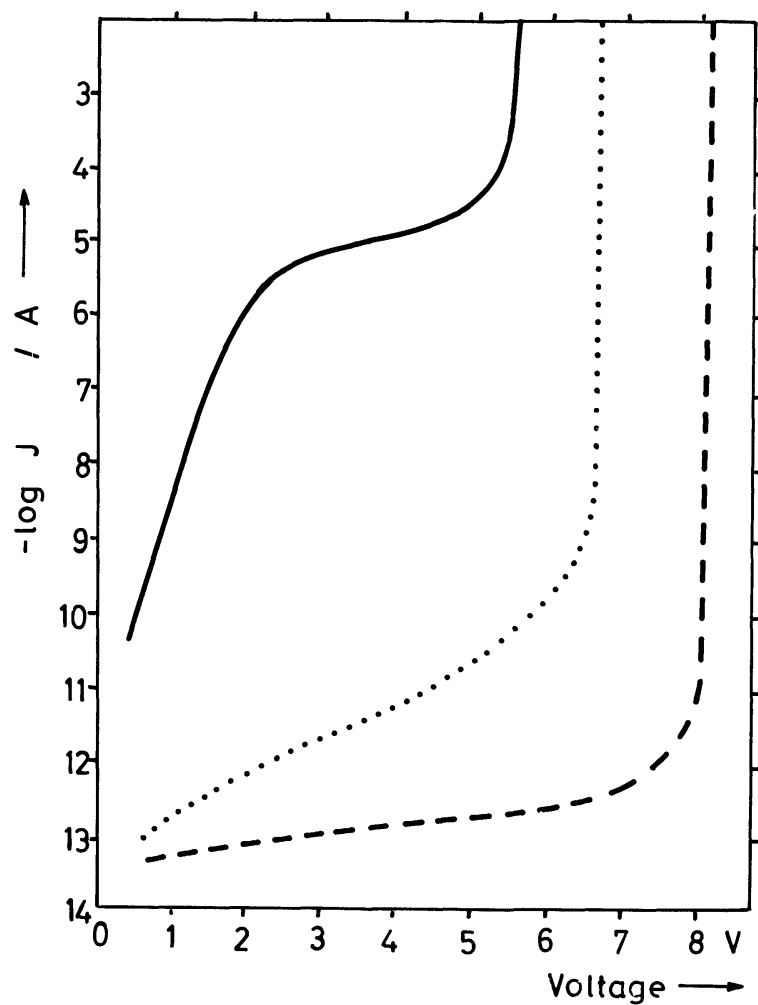

c)

FIG. 5. - 3D-transistor with medium leakage current. a) TEM image $(650 \mathrm{keV})$ revealing several dislocations in the emitter area. b) Results of stereo microscopy depicted in a schematic cross section of the transistor : only dislocations $2,3,4$ and 5 are crossing the pn-junctions. c) Electrical characteristics : $I_{\mathrm{CEO}} / U_{\mathrm{CE}}(-)$, $I_{\mathrm{CB}} / U_{\mathrm{CB}}(-\cdots), I_{\mathrm{EB}} / U_{\mathrm{EB}}(\cdots)$.

running through one of the pn-junctions did not exert any significant detrimental influence on the electrical characteristics.

A careful TEM analysis of the dislocation contrast did not reveal any decoration of the dislocations by impurity precipitates. This indicates that the increased emitter collector leakage current in cases where dislocations are crossing both the pn-junctions may be mainly attributed to real diffusion pipes [7], i.e. formation of a low resistive path between emitter and collector by enhanced diffusion of phosphorus dopant atoms at the dislocations (Fig. 5c). From Burgers vector analysis of the dislocations of figure 5 it is evident that they are mainly of edge character.

The generation of the dislocations observed is mainly due to : 1) The large stresses built up at the edges of the oxide wells (volume expansion of the $\mathrm{SiO}_{2}$ during oxidation, internal stresses of the silicon nitride layer) and 2) the existence of potential dislocation sources (e.g. glide zones, impurity precipitates, mechanical damage). The different type of dislocation sources occuring in wafers with and without an epitaxial layer may explain the fact that the dense oxide-edge dislocation arrays of figure $4 b$ are only observed in devices produced on epitaxial layers. The origin of the 


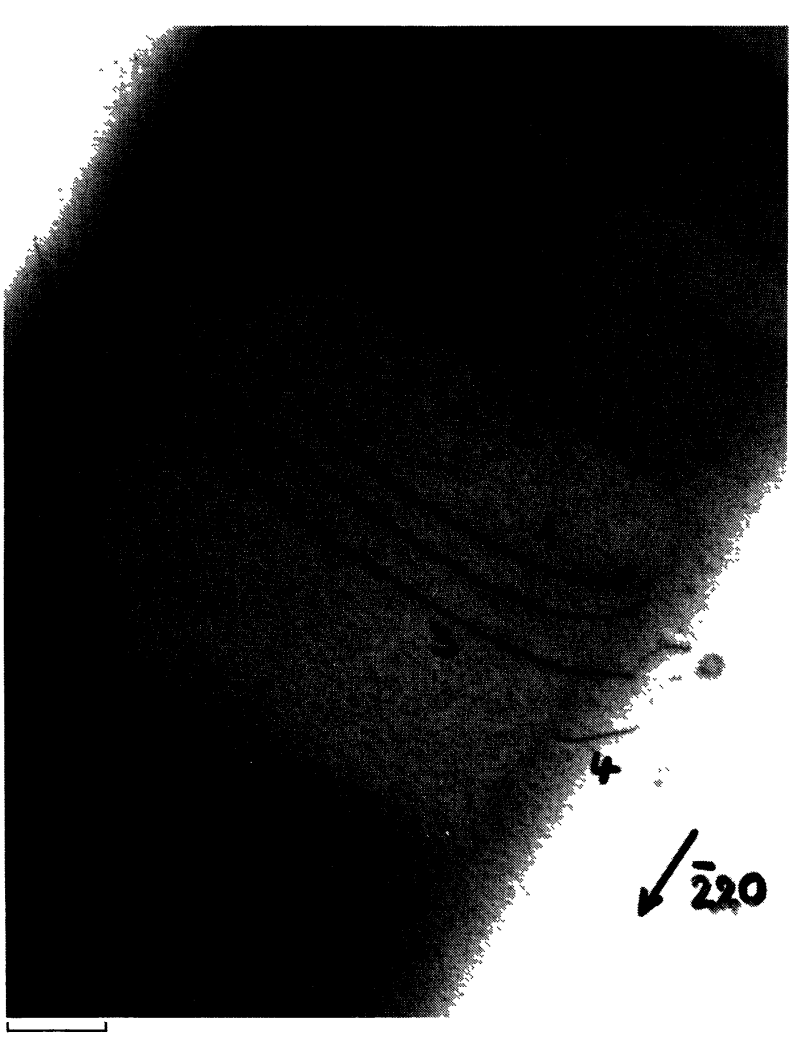

$1 \mu \mathrm{m}$

a)

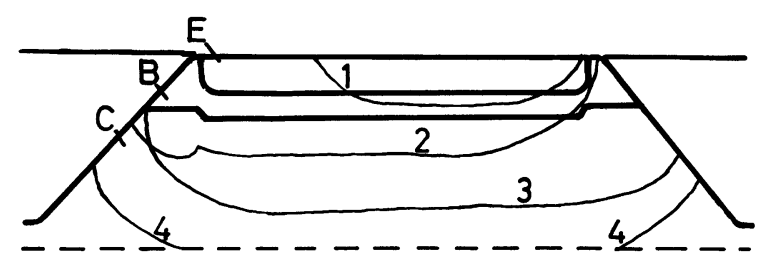

b)

microcraks may be attributed to an interaction of crystal defects and stresses at the silicon nitride edges.

Summarizing we have found two distinct peaks in the $I_{\text {CEO }}$ histogram. The small peak at $I_{\text {CEO }}$ levels $>10^{-4} \mathrm{~A}$

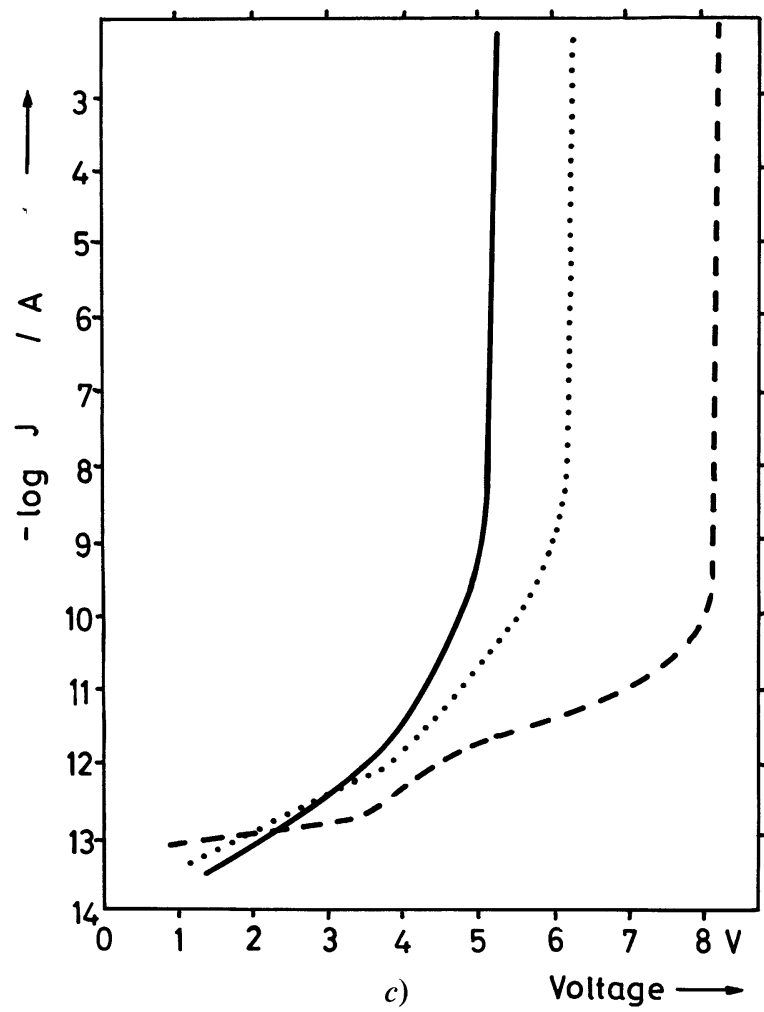

Fig. 6. - 3D-transistor with low leakage current (good device). a) TEM image exhibiting dislocations which do not penetrate both pn-junctions. b) Schematic cross section showing the results of stereo microscopy. c) Electrical characteristics : $I_{\mathrm{CEO}} / U_{\mathrm{CE}}(-)$,

$$
I_{\mathrm{CB}} / U_{\mathrm{CB}}(---), I_{\mathrm{EB}} / U_{\mathrm{EB}}(\cdots) \text {. }
$$

is caused by microcracks and/or dislocations in high density $\left(10^{8} \mathrm{~cm}^{-2}\right)$. No or a few dislocations are present in multi-emitter transistors belonging to the large peak at $I_{\mathrm{CEO}}<10^{-7} \mathrm{~A}$.

Acknowledgment. - We are indebted to Dr. H. Murrmann for his encouraging interest and to G. E. Schuh for his excellent technical assistance.

\section{References}

[1] Ernst, H., Glock, H., Rathbone, R., Schwabe, U., BürKER, U., Siemens Forsch. Entwicklungsber 6 (1977) 86.

[2] BUIE, J., Intercon (1975) 1.

[3] Kulkarni, M. H., Hasson, J. C., James, G. A. A., IEEE Trans. Electron. Devices ED-19 (1972) 1098.

[4] Grienauer, H., MaYer, K. R., Siemens-Z.60 (1976) 116.
[5] Föll, H., Kolbesen, B. O., Semiconductor Silicon (ed. by H. R. Huff and E. Sirtl) 1977, p. 740. The Electrochem. Soc. Inc. Princeton N. J. 1977.

[6] Kolbesen, B. O., Strunk, H., Proc. Fifth Int. Conf. High Voltage Electron Microscopy, Kyoto (1977) p. 637.

[7] Barson, F., IEEE SC-11 (1976) 505. 